\title{
Article \\ Semi-Active Control for a Helicopter with Multiple Landing Gears Equipped with Magnetorheological Dampers
}

\author{
Quoc Viet Luong $(\mathbb{D}$, Dae-Sung Jang and Jai-Hyuk Hwang *(i) \\ School of Aerospace and Mechanical Engineering, Korea Aerospace University, Goyang-si 10540, Korea; \\ lqviet@kau.kr (Q.V.L.); dsjang@kau.ac.kr (D.-S.J.) \\ * Correspondence: jhhwang@kau.ac.kr; Tel.: +82-02-300-0109
}

Citation: Luong, Q.V.; Jang, D.-S.; Hwang, J.-H. Semi-Active Control for a Helicopter with Multiple Landing Gears Equipped with Magnetorheological Dampers. Appl. Sci. 2021, 11, 3667. https://doi.org/ 10.3390/app11083667

Academic Editor: Lucyna Leniowska

Received: 24 March 2021

Accepted: 16 April 2021

Published: 19 April 2021

Publisher's Note: MDPI stays neutral with regard to jurisdictional claims in published maps and institutional affiliations.

Copyright: (c) 2021 by the authors. Licensee MDPI, Basel, Switzerland. This article is an open access article distributed under the terms and conditions of the Creative Commons Attribution (CC BY) license (https:/ / creativecommons.org/licenses/by/ $4.0 /)$.

\begin{abstract}
Due to their extensive use in various applications, helicopters need to be able to land in a variety of conditions. Typically, a helicopter landing gear system with skids or passive wheeldampers is designed based on only one critical touchdown condition. Thus, this helicopter landing gear system may not perform well in different landing conditions. A landing gear system with magnetorheological (MR) dampers would be a promising candidate to solve this problem. However, a semi-active controller must be designed to determine the electrical current applied to the MR damper to directly manage the damping force. This paper presents a new skyhook controller, called the skyhook extended controller, for a helicopter with multiple landing gears equipped with MR dampers to reduce the helicopter's acceleration at the center of gravity in off-normal landing attitude conditions. A 9-DOF simulation model of a helicopter with multiple MR landing gears was built using RECURDYN. To verify the effectiveness of the proposed controller, co-simulations were executed with RECURDYN and MATLAB in different initial pitch and roll angles at touchdown. The main simulation results show that the proposed controller can greatly decrease the peak and rms acceleration of the helicopter's center of gravity compared to a traditional skyhook controller and passive damper.
\end{abstract}

Keywords: helicopter landing systems; magnetorheological damper; skyhook control; semi-active control; skyhook extended control

\section{Introduction}

Helicopters are vertical take-off and landing aircraft able to hover, fly sideward, fly backward, and fly forward. They can perform other desirable maneuvers in civilian fields such as sea and mountain rescue, police surveillance, and firefighting, or in military missions such as battlefield surveillance, troop transport, assaults, and antitank operations [1]. In normal landing conditions, the pilot controls the rate of descent to ensure a smooth touchdown while the engine still operates, in a maneuver known as power-on landing [2]. However, common phenomena such as ground effect [1], ground resonance [3], and slope landings [4] can cause operational challenges and also significantly reduce landing gear performance. Moreover, during power-off landing maneuvers, there are more risks inherent in performing autorotation [1,2,4]. Typically, landing gears with skids or passive dampers are set up to improve safety and pilot comfort. However, they are also designed based on only one critical touchdown condition. Accordingly, there are limitations in landing performance in different landing cases. Thus, the development of a helicopter landing gear system is necessary to reduce vibration as well as to improve safety and pilot comfort during touchdown in different landing scenarios.

Thus far, many helicopter landing gear systems have been developed through experiments and theoretical studies. For example, Jae-Up et al. [5] applied a sky-hook control algorithm to improve the landing performance of a single helicopter landing gear with a magnetorheological (MR) damper. Saleh et al. [6] designed a helicopter skid landing 
gear system with an MR damper. The simple semi-active controller based on optimum Bingham numbers was applied to generate the desired yield force. Choi et al. $[7,8]$ designed and analyzed an adaptive landing gear system using an MR damper for a lightweight helicopter. In all the previous studies, helicopter landing gear systems equipped with MR dampers were among the most promising choices for enhancing performance and adaptability. However, the control algorithms were designed based on only one critical touchdown condition. Control problems with multiple landing gears being subjected to differing landing scenarios have not yet been fully investigated.

Skyhook control, which is the most popular control algorithm used in vehicle suspension systems, is a candidate to solve this problem. Skyhook control is simple and easy to understand because it needs little information on the system's state for implementation [9]. Skyhook control has proved its ability to reduce vehicle vibration, both with single suspension [10] or multiple suspensions [11]. The control objective of a suspension system of a vehicle is usually to attenuate vibration to improve driver comfort. However, the control target of a landing gear system of a helicopter is not only to improve the pilot's comfort but also to mitigate the impact of heavy shock on touchdown. Moreover, a helicopter's landing gear system must be tested with hard landing conditions [12], which can occur when the sink speed is larger than intended due to external factors, as mentioned earlier. Thus, the skyhook control in a helicopter's landing gear system needs to be properly modified, in contrast to the vehicle's suspension system.

The main contribution of this study is to develop an easy-to-implement control algorithm for a helicopter with multiple landing gears equipped with MR dampers, which reduces the acceleration at the helicopter's center of gravity under off-normal attitude conditions. As the first step, a 9-degree of freedom (DOF) helicopter model with multiple landing gears equipped with MR dampers was built using RECURDYN, which is a commercial multibody simulation software. In the second step, a control algorithm was designed based on the traditional skyhook control, called the skyhook extended control, to mitigate the magnitude of acceleration at the center of gravity with different initial pitch and roll angles. Co-simulations (RECURDYN-MATLAB) were then executed to verify the effectiveness of the controllers under differing landing scenarios.

This paper is organized as follows. Section 2 describes a helicopter with multiple landing gears equipped with MR dampers. In Section 3, the target of our controller is explained. In Section 4, the concept of our helicopter landing gear system is detailed. In Section 5, the control algorithms are developed under differing landing scenarios. In Section 6, the simulation results and discussions of the control algorithm are presented with respect to the landing scenarios. Section 7 presents a discussion of this study.

\section{A Helicopter with Multiple Landing Gears}

The helicopter referenced in this research is a light military model called the Eurocopter Fennec (see Figure 1). This helicopter has a maximum takeoff weight of $2250 \mathrm{~kg}$ [13]. It is equipped with skids that were designed and tested with an initial sink-speed of $2.54 \mathrm{~m} / \mathrm{s}$ based on the standards outlined in FAA Part 27 [14]. Landing gears with wheels are better than those with skids during contact with the ground in differing landing scenarios [2]. Moreover, light helicopters with three landing gears are more popular than those with four. Hence, we modeled a helicopter following Fennec but with three landing gears instead of the original skids in this study. In particular, we assumed that the landing gears were equipped with MR dampers, which have been regarded as a promising candidate to improve landing gear performance by controlling the damping force [9,15-17]. In our previous research, a single landing gear equipped with an MR damper for a small aircraft was designed [16,17], as can be seen in Figure 2. This landing gear was designed for a maximum sprung weight of $680 \mathrm{~kg}$ and an initial sink-speed of $3 \mathrm{~m} / \mathrm{s}$. Accordingly, the total maximum allowable weight of the aircraft with three landing gears of this type is $2040 \mathrm{~kg}$. This maximum weight was slightly less than our helicopter weight $(2040 \mathrm{~kg}<2250 \mathrm{~kg})$. However, the designed initial sink speed of this aircraft was larger than that of the helicopter 
$(3 \mathrm{~m} / \mathrm{s}>2.54 \mathrm{~m} / \mathrm{s})$. Thus, the landing gear equipped with the MR damper in our previous research was able to be used in our helicopter model with similar parameters that can be referred to in $[16,17]$.

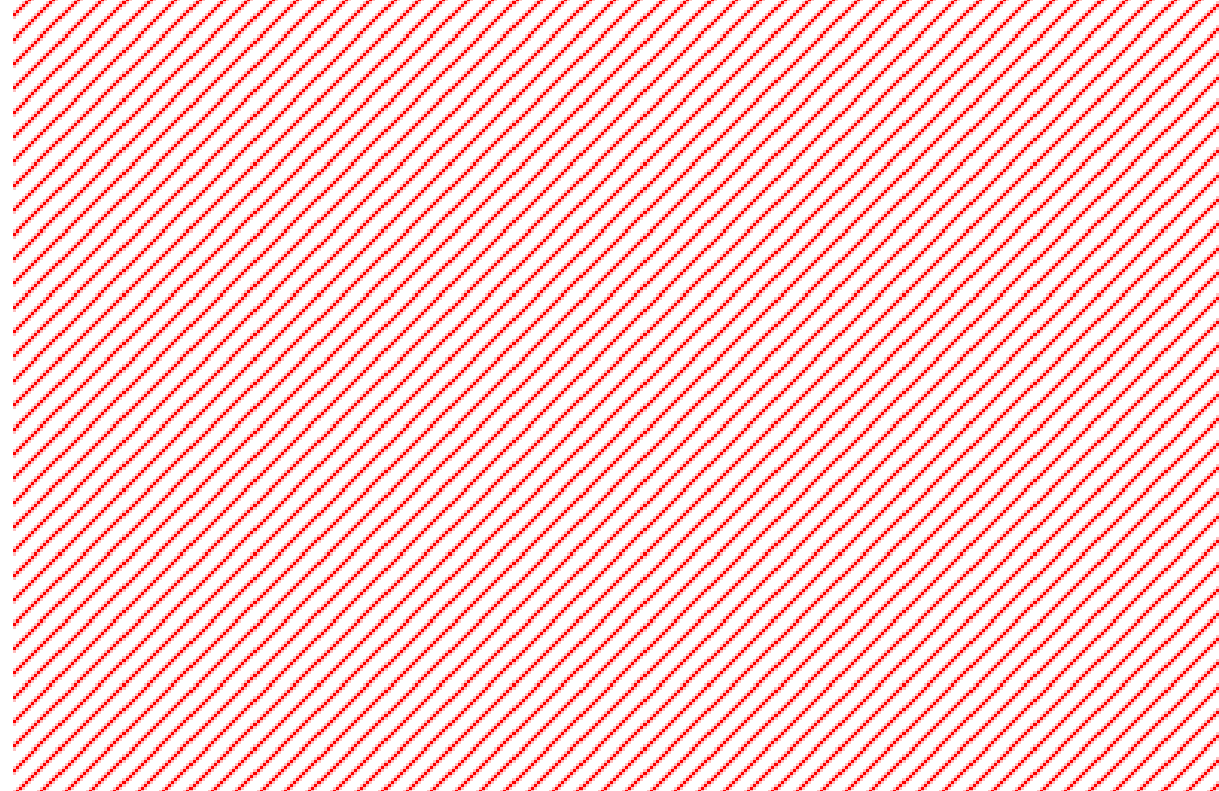

Figure 1. Eurocopter Fennec.

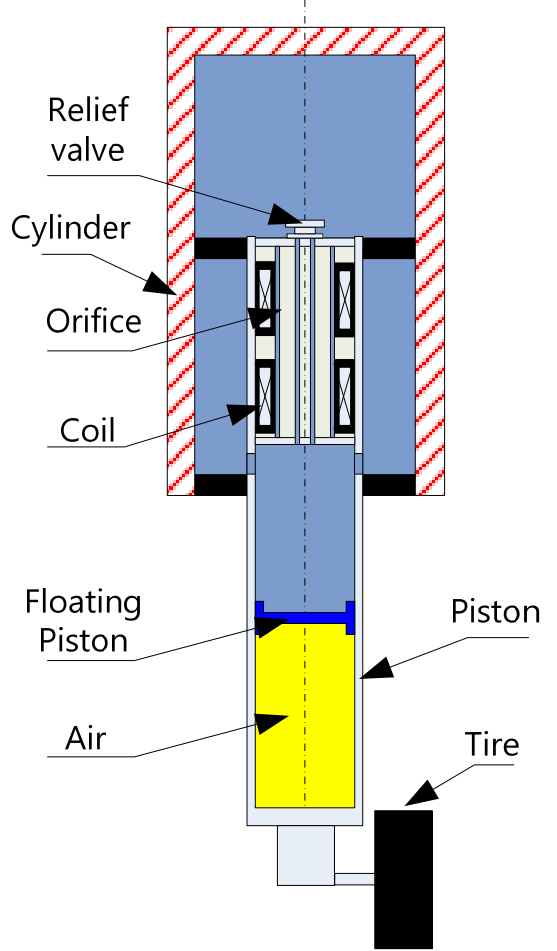

Figure 2. Structure of a landing gear equipped with an MR damper.

The 3D model of our helicopter equipped with three landing gears was drawn using RECURDYN (Figure 3). In this model, the 6-DOF helicopter body was assumed to be rigid and was set up for the initial parameters-i.e., the aircraft mass, moment of inertia, initial sink speed, initial pitch, and roll angle. It was assumed that there was no input power into the rotary wings, and there was no lift force on the helicopter. Hence, the power-off landing, 
which, as mentioned earlier, is the most dangerous case, was simulated in this research. The landing gear has mainly two parts: the upper part consists of the cylinder of the MR damper and a structure that connects to the bottom of the helicopter with fixed joints; and the lower part connects the damper piston and wheel assembly, which has 1-DOF movement along the cylinder. Thus, the helicopter with the three landing gears has 9-DOF in total. In this research, the damping force $\left(F^{d}\right)$ of the $i$ th landing gear $(i=\{1,2,3\}$ : nose landing gear, left main landing gear, and right main landing gear, respectively) is the combination of hydraulic force $\left(F^{v}\right)$, air force $\left(F^{a}\right)$, and MR force $\left(F^{M R}\right)$ which is described below:

$$
\begin{gathered}
F_{i}^{d}=F_{i}^{v}+F_{i}^{a}+F_{i}^{M R} \\
F_{i}^{v}=C \dot{s}_{i} \\
F_{i}^{a}=A_{P}\left(p_{0}\left(\frac{V_{0}}{V_{0}-A_{P} s_{i}}\right)^{n}-p_{A T M}\right) \\
F_{i}^{M R}=f\left(u_{i}, \dot{s}_{i}\right)
\end{gathered}
$$

where $s, \dot{s}$, are the stroke and stroke velocity, respectively. Without any the magnetic field applied, the MR fluid can be modeled as a Newtonian fluid. However, it behaves like a Bingham fluid if magnetic field is present and is able to sustain some shear stress in the direction normal to the magnetic flux. In the Bingham plastic model for MR fluid in [18], the yield shear stress of MR fluid, which is the origin of the MR force $\left(F^{M R}\right)$, is related directly to the magnetic field intensity. The MR damper model in this paper generates the magnetic field by the electrical current $u$ through the coil of the damper core at the top of the piston. The detailed model of the MR core is given in [15]. Moreover, the relationship between the tire and ground is set up by using "Tire Tool-Kit" inside RECURDYN. All helicopter parameters are listed in Table 1.

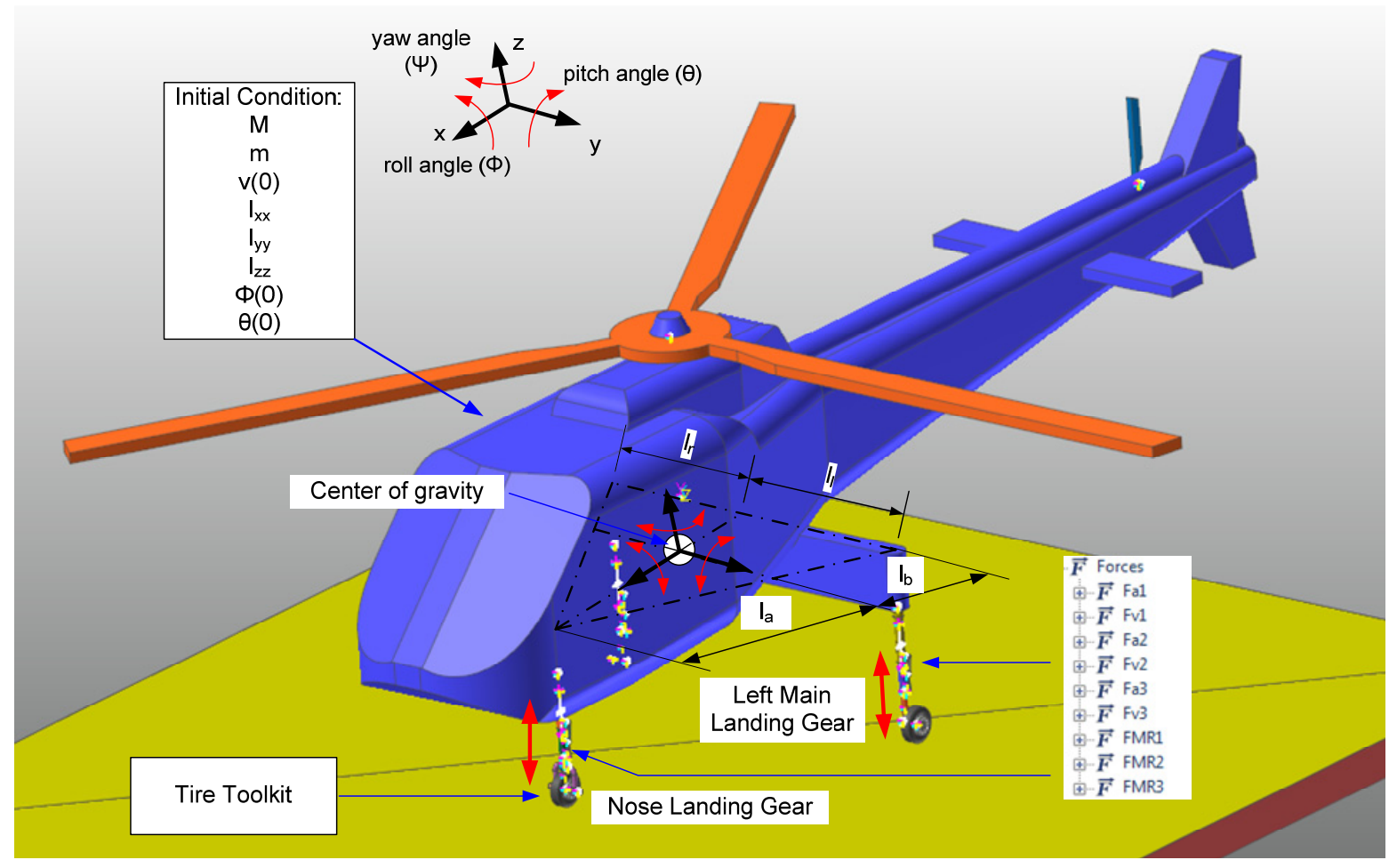

Figure 3. Helicopter with 3 landing gears in RECURDYN. 
Table 1. Helicopter parameters.

\begin{tabular}{|c|c|c|c|}
\hline Symbol & Quantity & Value & Unit \\
\hline$A_{p}$ & Cross-area of the head piston & $2.6 \times 10^{-3}$ & $\mathrm{~m}^{2}$ \\
\hline$b$ & Tire force index & 1.13 & \\
\hline C & Viscous damping coefficient & 7.0 & $\mathrm{kNs} / \mathrm{m}$ \\
\hline$g$ & Gravitational acceleration & 9.81 & $\mathrm{~m} / \mathrm{s}^{2}$ \\
\hline M & Sprung mass (helicopter mass) & 2250 & $\mathrm{~kg}$ \\
\hline$m$ & Un-sprung mass & $18 *$ & $\mathrm{~kg}$ \\
\hline$n$ & Polytropic process index & 1.3 & \\
\hline$p_{0}$ & Initial air chamber charging pressure & 810 & $\mathrm{kPa}$ \\
\hline$p_{A T M}$ & Atmospheric pressure & 101.3 & $\mathrm{kPa}$ \\
\hline$k_{T}$ & Tire force constant & 412 & $\mathrm{kN} / \mathrm{m}$ \\
\hline$V_{0}$ & Initial air chamber volume & $6.92 \times 10^{-4}$ & $\mathrm{~m}^{3}$ \\
\hline$u$ & Control input (electrical current) & $0 \sim 1$ & A \\
\hline$v(0)$ & Initial sink speed & 2.54 & $\mathrm{~m} / \mathrm{s}$ \\
\hline$l_{r}$ & $\begin{array}{l}\text { Distance between right main landing gear } \\
\text { interface and helicopter mass center }\end{array}$ & 1.5 & $\mathrm{~m}$ \\
\hline$l_{l}$ & $\begin{array}{l}\text { Distance between left main landing gear } \\
\text { interface and helicopter mass center }\end{array}$ & 1.5 & $\mathrm{~m}$ \\
\hline$l_{a}$ & $\begin{array}{c}\text { Distance between nose landing gear interface } \\
\text { and helicopter mass center }\end{array}$ & 1.73 & $\mathrm{~m}$ \\
\hline$l_{b}$ & $\begin{array}{c}\text { Distance between main landing gear interface } \\
\text { and helicopter mass center }\end{array}$ & 0.87 & $\mathrm{~m}$ \\
\hline$I_{x x}$ & Roll mass moment of inertia & 79.1 & $\mathrm{kgm}^{2}$ \\
\hline$I_{y y}$ & Pitch mass moment of inertia & 2030.6 & $\mathrm{kgm}^{2}$ \\
\hline$I_{z z}$ & Yaw mass moment of inertia & 2317.2 & $\mathrm{kgm}^{2}$ \\
\hline$\Phi$ & Roll angle & $0-7$ & $\circ$ \\
\hline$\theta$ & Pitch angle & $0-7$ & $\circ$ \\
\hline
\end{tabular}

* The un-sprung mass includes the piston, MR fluid, wheel, etc. The total weight of MR damper alone, consisting of the piston, lower body except the wheel, and cylinder assembly, is about $15 \mathrm{~kg}$.

\section{Landing Gear System of the Helicopter}

Figure 4 shows the control architecture of our helicopter landing gear system. Since the weight of the landing gears and the cost of the measurement instruments are constrained, each landing gear is assumed to have only a position sensor that measures relative motion (i.e., stroke of the cylinder and piston). The helicopter control system includes accelerometers and gyroscopes that provide the aircraft's acceleration and three-axis rotation rates at the center of gravity, and it can be used to control the landing gears. The control strategy in our system determines the required electrical current to each landing gear after receiving the sensor signals. The electrical current is then applied to the MR dampers to generate the damping force to claim the control target. Developing a controller is challenging because this system is a multiple-input multiple-output (MIMO) system with nonlinear characteristics. 


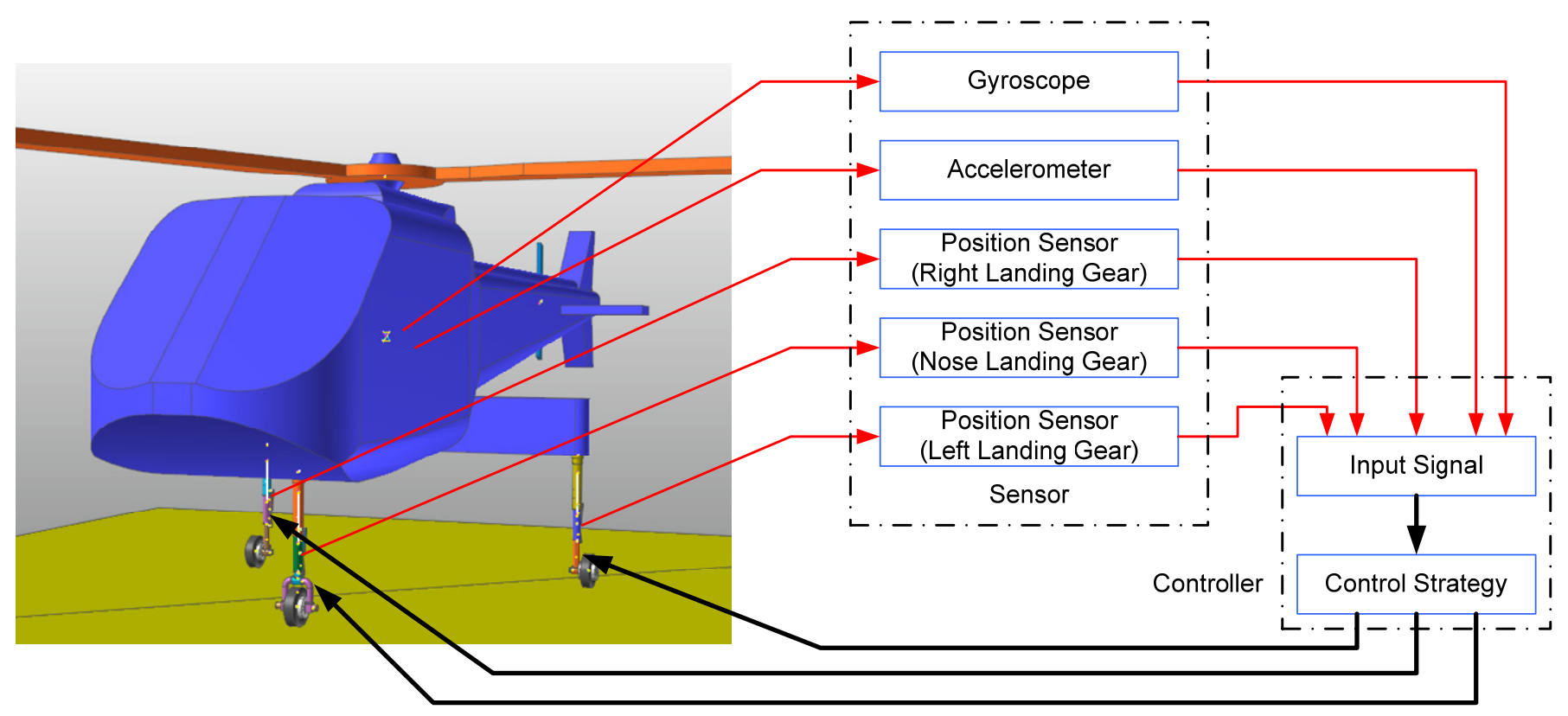

Figure 4. The control architecture of a helicopter landing gear system.

\section{Control Target}

During touchdown, there are two main goals for a typical landing gear, which are to improve total energy absorber efficiency and to reduce the magnitude of acceleration at the center of gravity of the helicopter.

The total energy absorber efficiency is a metric to assess the percentage of the mechanical energy that is absorbed by a landing gear during touchdown $[17,19]$. Figure 5 depicts an efficiency curve, which shows the relationship of the damping force and the stroke of a typical single landing gear while absorbing landing shock. It adequately represents the damping behavior after touchdown because the absorption and release of energy are simply determined by the area below the curve. The total energy absorber efficiency is defined by the ratio between the total energy absorbed by the landing gear and the product of maximum damping force and maximum stroke [17].

$$
\eta_{i}=\frac{\int_{0}^{s_{\text {final }}} F_{i}^{d} d s_{i}}{s_{i}^{\max } F_{i}^{\max }}
$$

where $s_{i}^{\max }, F_{i}^{\max }$ are the maximum stroke and maximum damping force, respectively, and $s_{\text {final }}$ is the final value of stroke at the total time for a landing test. This efficiency is easy to understand and to compute in an aircraft model with a single landing gear with two degrees of freedom in vertical motions. However, it is difficult to extend this concept to a higher DOF aircraft with multiple landing gears to measure the performance in off-normal landing cases because each landing gear is attached at a different position of the aircraft and behaves in a considerably different manner than the case presented in the typical load-stroke curve in Figure 5.

The realistic and plausible goal is to reduce the acceleration of the helicopter at its center of gravity $[20,21]$. An exemplar time history of helicopter acceleration at the center of gravity is presented in Figure 6. There are two salient tasks needed to claim this goal. One is to reduce the maximum absolute value for mitigating the large shock to the helicopter structure. The other is to reduce the average magnitude of acceleration, specifically in the 
rms value, during the entire landing phase to improve pilot and crew comfort. Thus, the cost function is designed as shown below.

$$
J=\max (|a|)+\frac{1}{t_{\text {final }}} \sqrt{\int_{0}^{t_{\text {final }}} a^{2} d t}
$$

where $a$ is the acceleration of the helicopter at its center of gravity and $t_{\text {final }}$ is the total time for a landing test. The main control target is set to reduce this cost function in differing off-normal attitude conditions on landing.

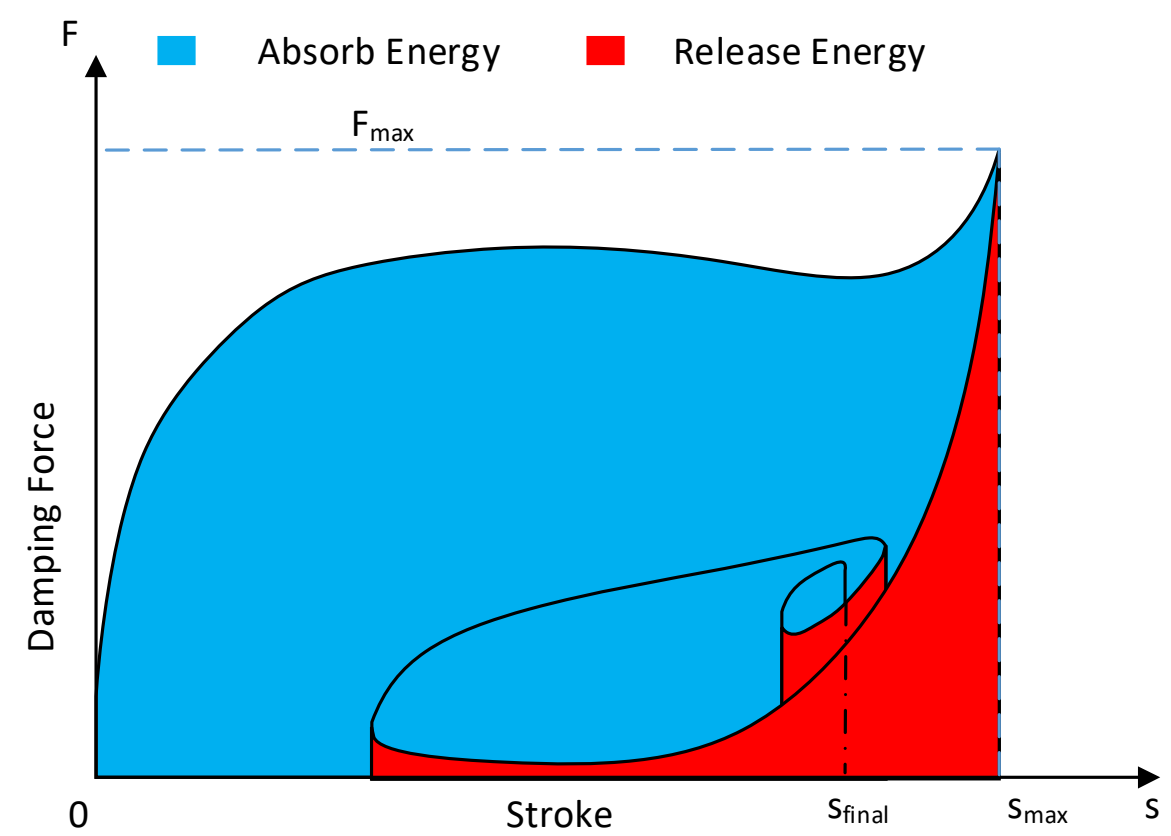

Figure 5. Load-stroke curve.

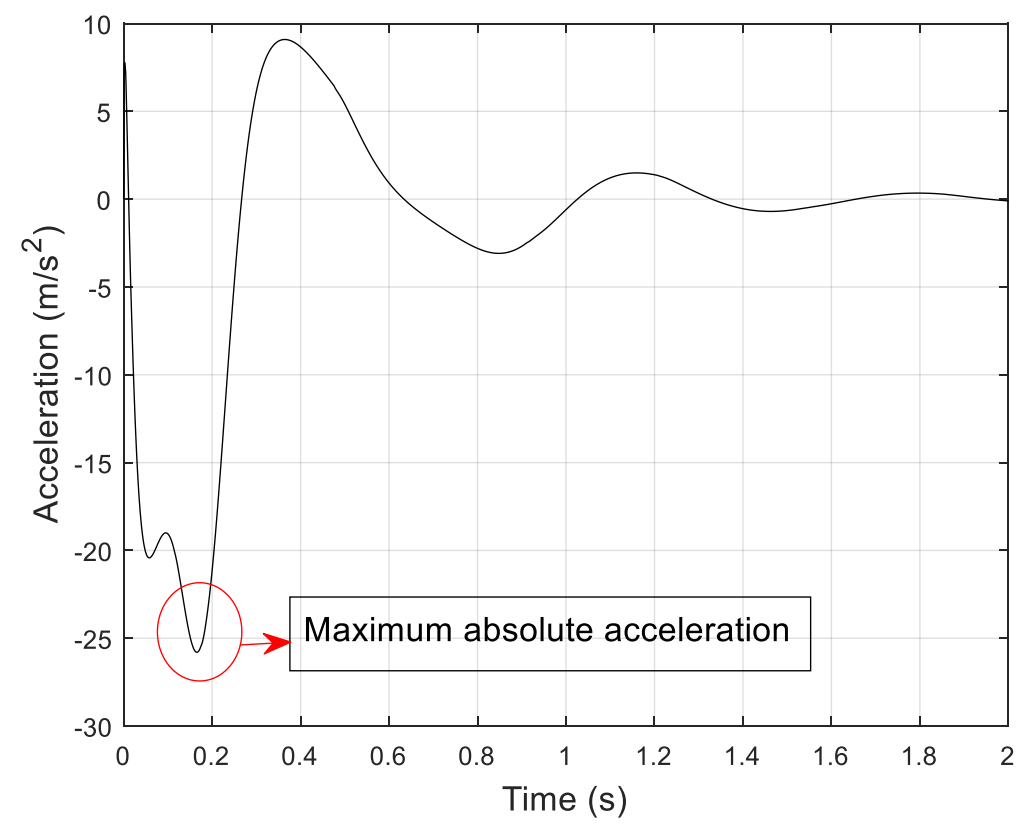

Figure 6. A typical acceleration time history of a helicopter at the center of gravity. 


\section{Control Design}

The traditional skyhook control algorithm was first suggested by Karnopp [22]. It subsequently became one of the most popular control methods used in vehicle suspensions to reduce vibration [11]. It has also been used to control landing gear systems with MR dampers $[9,23]$. Figure 7 shows the conceptual diagram of the traditional skyhook controller for our target helicopter with three landing gears equipped with MR dampers. It applies three translational virtual dampers that connect the helicopter and the imaginary support fixed in the sky. The skyhook controller has to control the MR dampers that emulates the behavior of the virtual dampers. Each virtual damper is connected to the helicopter at the position where a landing gear is attached. Thus, the traditional skyhook controller only reduces the vibration of a local motion of a part of the helicopter around each landing gear. In a semi-active controller, whose controllable damping force can be applied only in the opposite direction of the stroke velocity, the skyhook control law that is used for the $i$ th landing gear is given as

$$
u_{i}=\left\{\begin{array}{cc}
C_{i} v_{i}, & v_{i} \dot{s}_{i} \geq 0 \\
0, & v_{i} \dot{s}_{i}<0
\end{array}\right.
$$

where $C_{i}>0$ is the skyhook gain, $v_{\mathrm{i}}$ is the velocity of the point where the $i$ th landing gear is attached to the main body, and $\dot{s}_{i}$ is the stroke velocity of the $i$ th landing gear. It is assumed that no sensor can directly measure $v_{i}$ due to the practical limitations on weight and cost. However, the velocities can be estimated by following the approximate equations below.

$$
\begin{gathered}
v_{1} \approx v+l_{a} \dot{\theta} \\
v_{2} \approx v-l_{b} \dot{\theta}+l_{l} \dot{\phi} \\
v_{3} \approx v-l_{b} \dot{\theta}-l_{r} \dot{\phi}
\end{gathered}
$$

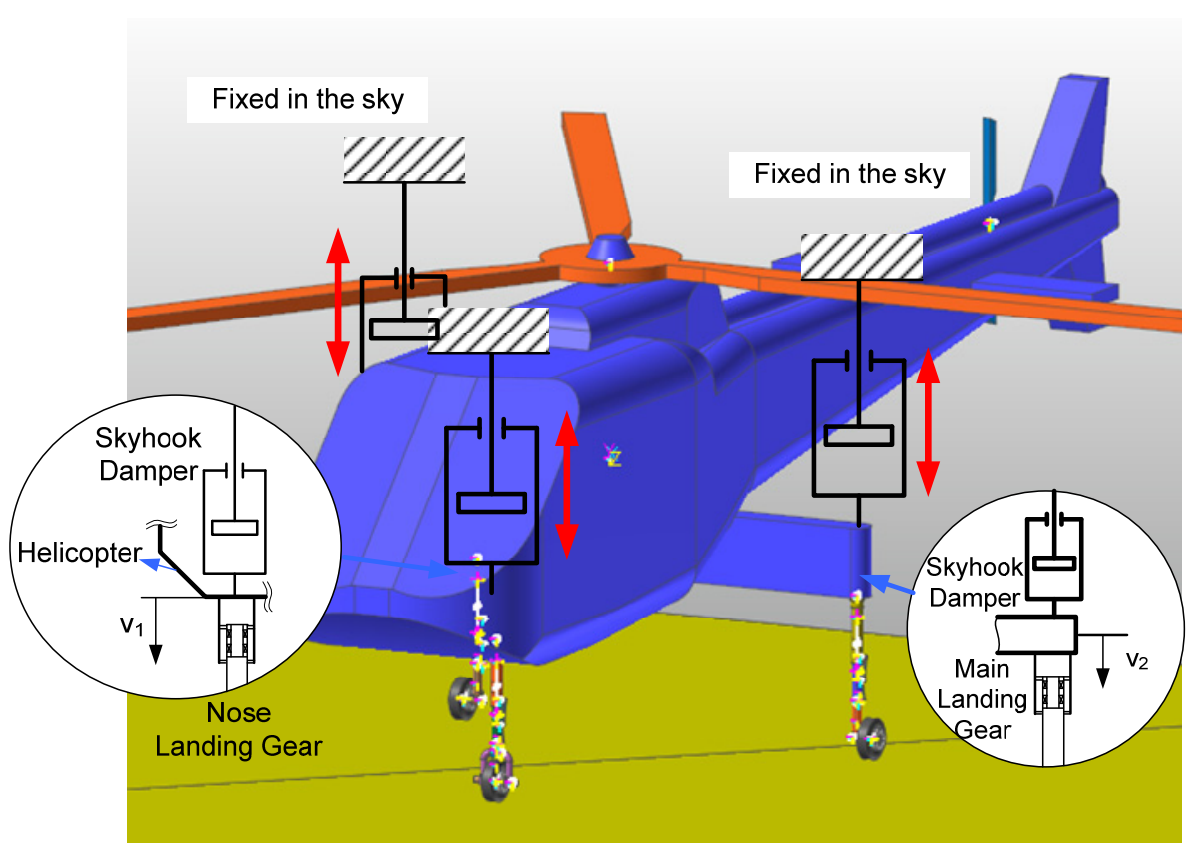

Figure 7. Concept of traditional skyhook control for the helicopter with 3 landing gears.

Note that the control input $(u)$ is a function of the sink speed $(v)$ of the main body, pitch rate $(\dot{\theta})$, and roll rate $(\dot{\phi})$. For each landing gear, there is only one parameter to adjust the control input in various landing situations. To extend this control strategy to have more parameters for tuning the control input, a extended control algorithm for skyhook is presented in this study. Figure 8 shows the concept of the skyhook extended controller. It sets three virtual dampers-i.e., a vertical translational damper and two rotational dampers-against the motion of the center of gravity and this connects the 
helicopter center and imaginary translation/rotation-free supports fixed in the sky. The skyhook extended controller must control each MR damper which emulates the behavior of one of the three virtual dampers. The skyhook extended control law is given as follows.

$$
u_{i}=C_{i}^{v} v+C_{i}^{\theta} \dot{\theta}+C_{i}^{\phi} \dot{\phi}
$$

where $C_{i}^{v}, C_{i}^{\theta}$, and $C_{i}^{\phi}$ are the skyhook gains, which can have a positive or negative value. However, the control input must follow the semi-active condition, which is given by

$$
\begin{gathered}
F_{i}^{M R}=\left\{\begin{array}{cc}
\operatorname{sat}\left(u_{i}\right), & u_{i} \dot{s}_{i} \geq 0 \\
0, & u_{i} \dot{s}_{i}<0
\end{array}\right. \\
\operatorname{sat}(x)=\left\{\begin{array}{cc}
1, & x \geq 1 \\
x, & 0 \leq x \leq 1 \\
0, & x \leq 0
\end{array}\right.
\end{gathered}
$$

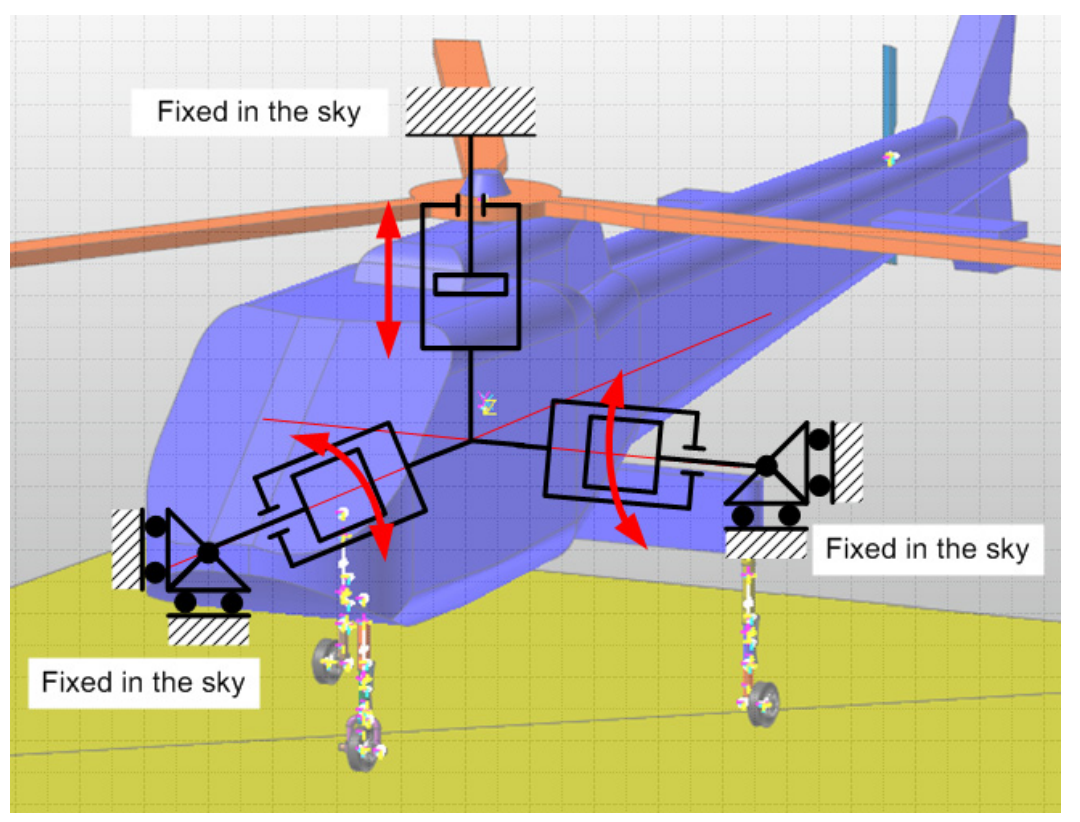

Figure 8. Concept of skyhook extended control for the helicopter with 3 landing gears.

As mentioned in Section 4, the main control objective is to reduce the helicopter acceleration at the center of gravity for differing initial pitch and roll angles. Therefore, the skyhook gains in the controllers (both traditional skyhook and the proposed extended version) must be determined in the various landing scenarios by using a look-up table method (refer to Figure 9). The most popular and traditional search methods to find an optimal parameter are gradient methods such as the steepest descent. However, these methods need to calculate the derivative of the cost function. In our system, it is difficult to calculate this derivative. Thus, the Nelder-Mead simplex method, a derivative-free optimization technique $[24,25]$, is adopted in this research. This method conveniently locates a local optimization point near an initial estimate. It is very suitable in our system because the result in a landing scenario can subsequently be employed as the initial estimate of the next landing scenario. The algorithm of this method is shown in Figure 10. 


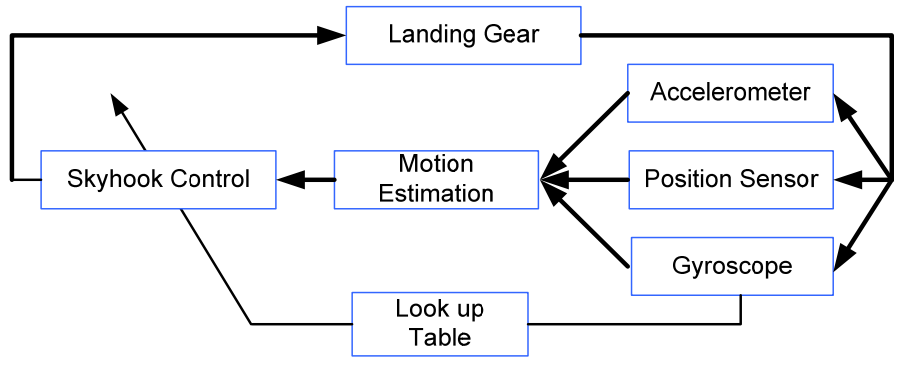

Figure 9. Skyhook controller block diagram.

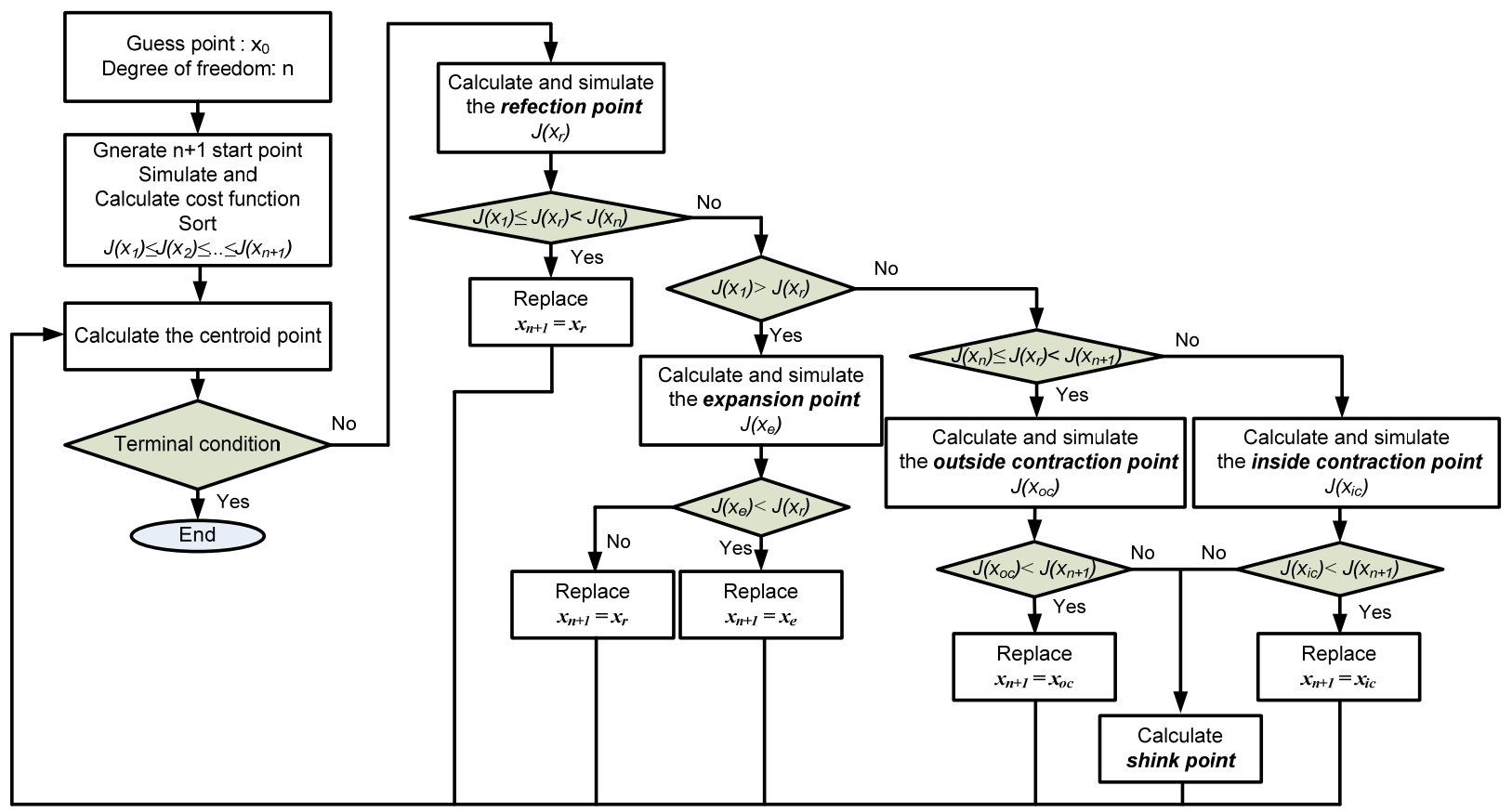

Figure 10. Nelder-Mead simplex method.

At the beginning, the unknown parameters (i.e., the skyhook gains) are put into a vector $x=\{C\}^{n}$ of $n$ dimensions $(n=3$ in the case of the traditional skyhook and $n=9$ for the skyhook extended controller). From here, $n$ starting points are then generated from the initial estimate $\left(x_{0}\right)$ which is given by

$$
x_{i}=x_{0}+k \varepsilon_{i}(\text { for } i=1: n)
$$

and the $n+1$ th starting point is calculated as

$$
x_{n+1}=x_{0}+k[1,1, \ldots, 1,]^{T}
$$

where $\varepsilon_{\mathrm{i}}$ is the unit vector of the $i$ th dimension, and $k$ is a scalar gain. Each starting point, (i.e., set of skyhook gains) is then evaluated with the numerical simulation in a landing scenario. The centroid point is calculated by averaging the $n$ best vertices according to the cost function (Equation (6)).

$$
\bar{x}=\frac{1}{n} \sum_{i=1}^{n} x_{i}
$$

The algorithm proceeds with a series of branching statements while computing the following five specific searching points:

reflection point $\left(x_{r}\right)$,

$$
x_{r}=\bar{x}+\alpha\left(\bar{x}-x_{n+1}\right)
$$


expansion point $x_{e}$

$$
x_{e}=\bar{x}+\beta\left(x_{r}-\bar{x}\right)
$$

outside contraction point $x_{o c}$,

$$
x_{o c}=\bar{x}+\gamma\left(x_{r}-\bar{x}\right)
$$

inside contraction point $x_{i c}$

$$
x_{i c}=\bar{x}-\gamma\left(x_{r}-\bar{x}\right)
$$

and the sink point,

$$
x_{i}=\bar{x}+\delta\left(x_{i}-\bar{x}_{1}\right)
$$

with $2 \leq i \leq n+1$. Each of the equations above is associated with a scalar parameter that is chosen according to the following [26].

$$
\alpha=1, \beta=1+\frac{2}{n}, \gamma=0.75-\frac{1}{2 n}, \delta=1-\frac{1}{n}
$$

The overall procedure of the Nelder-Mead simplex method is summarized in Figure 10. The terminal condition is given as

$$
\left|J\left(x_{1}\right)-J(\bar{x})\right| \leq \xi
$$

where $\xi=0.1$ is chosen in this study.

Figure 11 shows the simulation result of the Nelder-Mead simplex method for the tra-

\begin{tabular}{|c|c|c|c|c|c|c|c|c|c|c|c|c|c|c|}
\hline \multirow[b]{2}{*}{ Case } & \multicolumn{2}{|c|}{$\begin{array}{l}\text { Landing } \\
\text { Condition }\end{array}$} & \multicolumn{3}{|c|}{$\begin{array}{c}\text { Traditional } \\
\text { Skyhook Controller }\end{array}$} & \multicolumn{9}{|c|}{ Skyhook Extended Controller } \\
\hline & $\begin{array}{c}\text { Pitch } \\
\text { Angle } \\
\text { (deg) }\end{array}$ & $\begin{array}{c}\text { Roll } \\
\text { Angle } \\
\text { (deg) }\end{array}$ & $\begin{array}{c}C_{1} \\
(\mathrm{As} / \mathrm{m})\end{array}$ & $\begin{array}{c}C_{2} \\
(\mathrm{As} / \mathrm{m})\end{array}$ & $\begin{array}{c}C_{3} \\
(\mathrm{As} / \mathrm{m})\end{array}$ & $\begin{array}{c}C_{1}^{v} \\
\text { (As/m) }\end{array}$ & $\begin{array}{c}C_{1}^{\theta} \\
\text { (As/rad) }\end{array}$ & $\begin{array}{c}C_{1}^{\phi} \\
\text { (As/rad) }\end{array}$ & $\begin{array}{c}C_{2}^{v} \\
(\mathrm{As} / \mathrm{m})\end{array}$ & $\begin{array}{c}C_{2}^{\theta} \\
\text { (As/rad) }\end{array}$ & $\begin{array}{c}C_{2}^{\phi} \\
\text { (As/rad) }\end{array}$ & $\begin{array}{c}C_{3}^{v} \\
(\mathrm{As} / \mathrm{m})\end{array}$ & $\begin{array}{c}C_{3}^{\theta} \\
\text { (As/rad) }\end{array}$ & $\begin{array}{c}C_{3}^{\phi} \\
\text { (As/rad) }\end{array}$ \\
\hline 1 & 0 & 0 & 0.5 & 0.5 & 0.5 & 0.25 & 0.24 & 0.06 & 0.50 & 0.25 & 0.25 & 0.24 & 0.16 & 0.24 \\
\hline 2 & 1 & 0 & 0.52 & 0.47 & 0.47 & 0.39 & 0.38 & 0.37 & 0.39 & -0.03 & 0.36 & 0.39 & 0.39 & 0.38 \\
\hline 3 & 3 & 0 & 0.51 & 0.37 & 0.38 & 0.64 & 0.64 & 0.47 & 0.64 & -0.05 & 0.64 & 0.64 & 0.64 & 0.64 \\
\hline 4 & 5 & 0 & 0.5 & 0.5 & 0.5 & -0.17 & -0.19 & 0.45 & 2.98 & 2.64 & 4.25 & 2.45 & 2.18 & 3.31 \\
\hline 5 & 7 & 0 & 1.19 & 1.38 & 1.4 & -0.17 & -0.18 & 0.44 & 2.90 & 2.57 & 4.13 & 2.37 & 2.11 & 3.22 \\
\hline 6 & 0 & 1 & 0.45 & 0.38 & 0.61 & 0.37 & 0.06 & 0.33 & 0.38 & 0.29 & 0.38 & 0.34 & 0.24 & 0.33 \\
\hline 7 & 1 & 1 & 0.67 & 0.10 & 0.35 & 0.44 & 0.44 & 0.09 & 0.44 & 0.44 & 0.35 & 0.44 & 0.44 & 0.44 \\
\hline 8 & 3 & 1 & 0.54 & 0.25 & 0.40 & 0.92 & 0.92 & 0.92 & 0.92 & 0.92 & 0.80 & 0.92 & 0.92 & -0.14 \\
\hline 9 & 5 & 1 & 0.50 & 0.46 & 0.56 & 3.00 & 3.00 & 0.00 & 3.00 & 3.00 & 2.10 & 3.00 & 3.00 & 2.60 \\
\hline 10 & 7 & 1 & 0.30 & 2.31 & 1.73 & 0.40 & 0.45 & 0.32 & 1.50 & 1.35 & 1.97 & 1.25 & 1.13 & 1.47 \\
\hline 11 & 0 & 3 & 0.54 & 0.28 & 0.94 & 0.76 & 1.31 & 0.01 & 0.01 & 0.01 & 0.01 & 1.04 & -0.90 & -1.56 \\
\hline 12 & 1 & 3 & 0.53 & 0.14 & 0.66 & 0.46 & -0.80 & 0.01 & 0.09 & -0.08 & 0.13 & 0.78 & -0.67 & -1.16 \\
\hline 13 & 3 & 3 & 0.72 & 0.21 & 0.39 & 1.03 & 1.03 & -0.09 & 1.03 & 1.03 & 0.80 & 1.03 & 1.03 & 1.03 \\
\hline 14 & 5 & 3 & 0.62 & 0.36 & 0.46 & 4.30 & 4.30 & 0.00 & 4.30 & 4.26 & 3.68 & 4.30 & 4.30 & 3.01 \\
\hline 15 & 7 & 3 & 0.52 & 0.52 & 0.54 & 0.08 & -0.15 & 0.00 & 3.13 & 2.66 & 4.61 & 3.44 & 2.98 & -5.16 \\
\hline 16 & 0 & 5 & 0.65 & 0.39 & 0.48 & 0.71 & -1.23 & 0.00 & 0.04 & 0.03 & 0.05 & 0.98 & 0.84 & -1.46 \\
\hline 17 & 1 & 5 & 0.69 & 0.03 & 0.80 & 0.62 & -1.03 & 0.02 & 0.19 & 0.16 & 0.27 & 0.72 & 0.63 & -1.04 \\
\hline 18 & 3 & 5 & 0.57 & 0.43 & 0.52 & 0.98 & 0.98 & -0.15 & 0.98 & 0.98 & 0.98 & 0.98 & 0.98 & 0.98 \\
\hline 19 & 5 & 5 & 0.65 & 0.39 & 0.61 & 5.14 & 5.14 & 0.00 & 5.14 & 5.14 & 3.53 & 5.14 & 5.14 & 4.47 \\
\hline 20 & 7 & 5 & 0.61 & 0.65 & 0.67 & 0.16 & 0.23 & 0.00 & 5.30 & 4.62 & -7.38 & 5.88 & 5.12 & 8.71 \\
\hline 21 & 0 & 7 & 0.76 & 0.27 & 0.73 & 0.77 & -1.28 & 0.02 & -0.11 & -0.10 & -0.17 & 1.16 & 1.01 & -1.70 \\
\hline 22 & 1 & 7 & 0.50 & 0.43 & 0.61 & 0.53 & -0.91 & 0.00 & 0.33 & 0.29 & 0.50 & 0.63 & 0.55 & -0.95 \\
\hline 23 & 3 & 7 & 0.60 & 0.33 & 0.60 & 0.50 & 2.00 & 0.00 & 0.35 & 2.60 & 1.50 & 2.60 & 0.55 & 3.00 \\
\hline 24 & 5 & 7 & 0.62 & 0.35 & 0.64 & 4.50 & 4.50 & 0.00 & 4.50 & 4.50 & 3.15 & 4.50 & 4.50 & 3.90 \\
\hline 25 & 7 & 7 & 0.65 & 0.69 & 0.80 & 2.57 & 2.57 & 2.57 & 2.57 & 2.57 & -0.03 & 2.57 & 2.57 & 1.61 \\
\hline
\end{tabular}
ditional skyhook controller and the skyhook extended controller in three landing scenarios cases. It was observed that the algorithm produced the local optimal value after around 20 loops. The skyhook gains of the controllers in the explored cases of initial pitch and roll angles are given in Table 2.

Table 2. Skyhook gain table. 


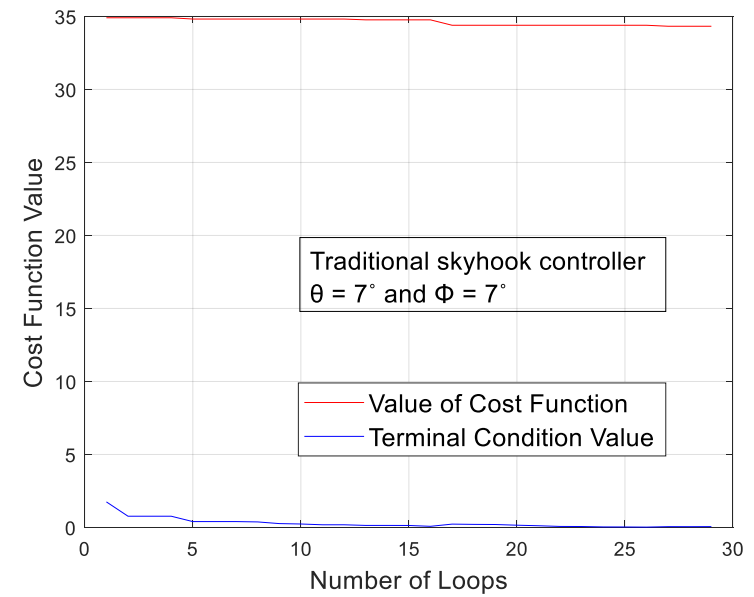

(a)

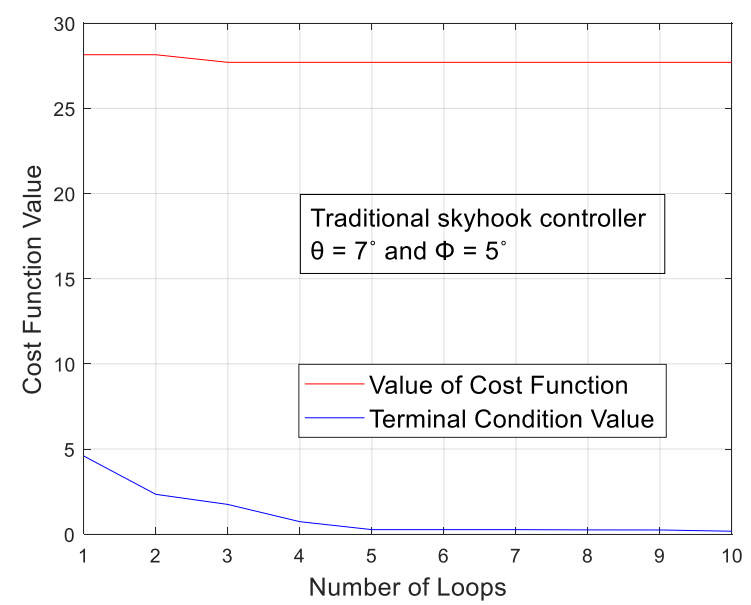

(c)

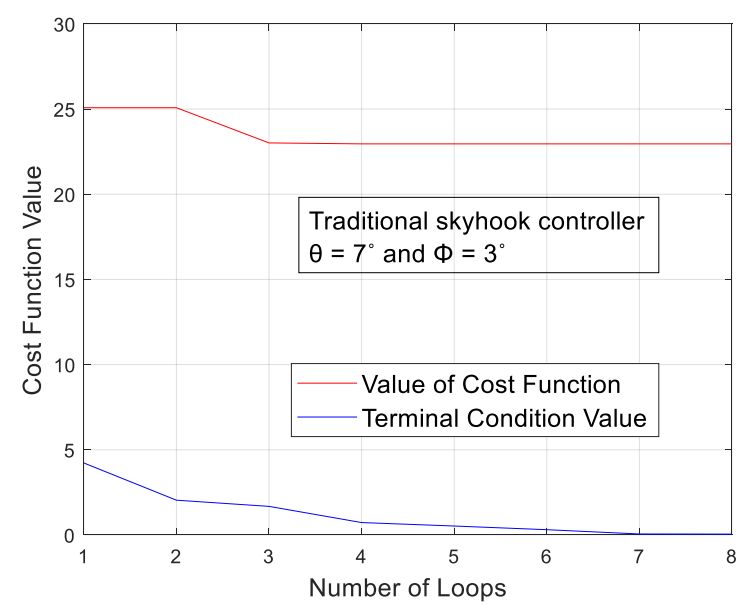

(e)

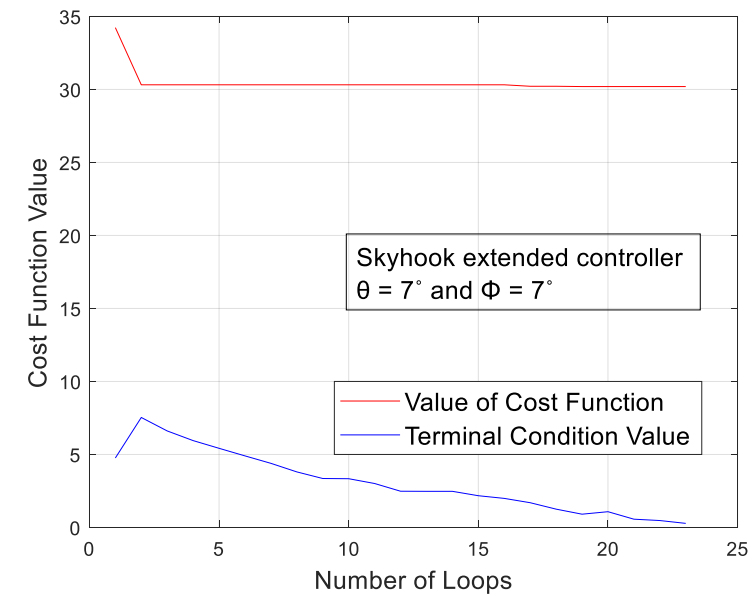

(b)

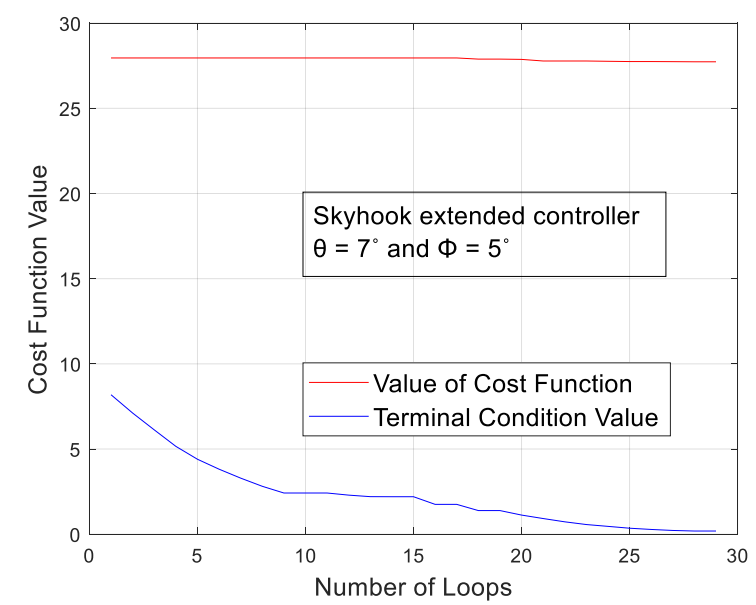

(d)

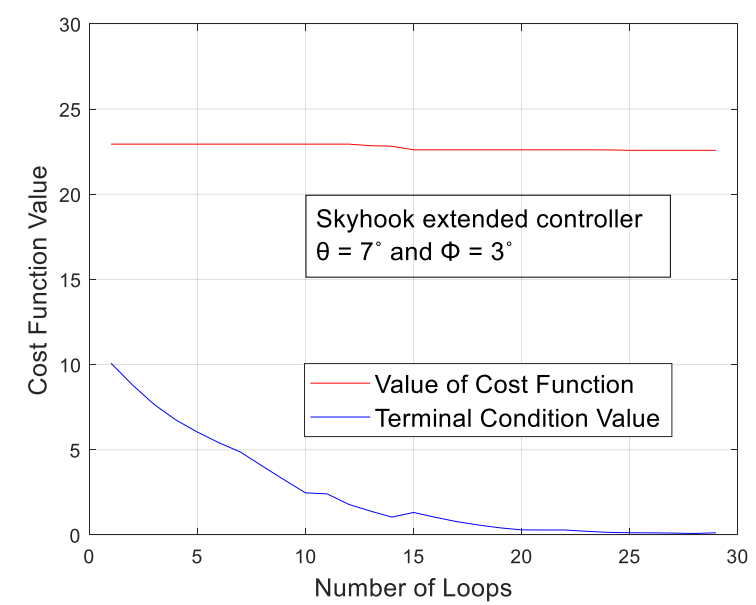

(f)

Figure 11. Simulation results of the Nelder-Mead simplex method in the case of $(\mathbf{a}, \mathbf{b}) \theta=7^{\circ}$ and $\Phi=7^{\circ} ;(\mathbf{c}, \mathbf{d}) \theta=7^{\circ}$ and $\Phi=5^{\circ} ;(\mathbf{e}, \mathbf{f}) \theta=7^{\circ}$ and $\Phi=3^{\circ} .(\mathbf{a}, \mathbf{c}, \mathbf{e})$ Traditional skyhook controller; $(\mathbf{b}, \mathbf{d}, \mathbf{f})$ Skyhook extended controller.

\section{Simulation Results}

To verify the effectiveness of the proposed controller in off-normal landing conditions, numerical simulations were executed with various initial pitch and roll angles. All simulations were set up and processed based on the co-simulation framework linked 
between MATLAB and RECURDYN (as can be seen in Figure 12). In this framework, Simulink-MATLAB is the host that runs the controller algorithm and environment for the co-simulation, while RECURDYN is the client that receives electrical current signals from the controller and then returns the state of the system and damping force to MATLAB.

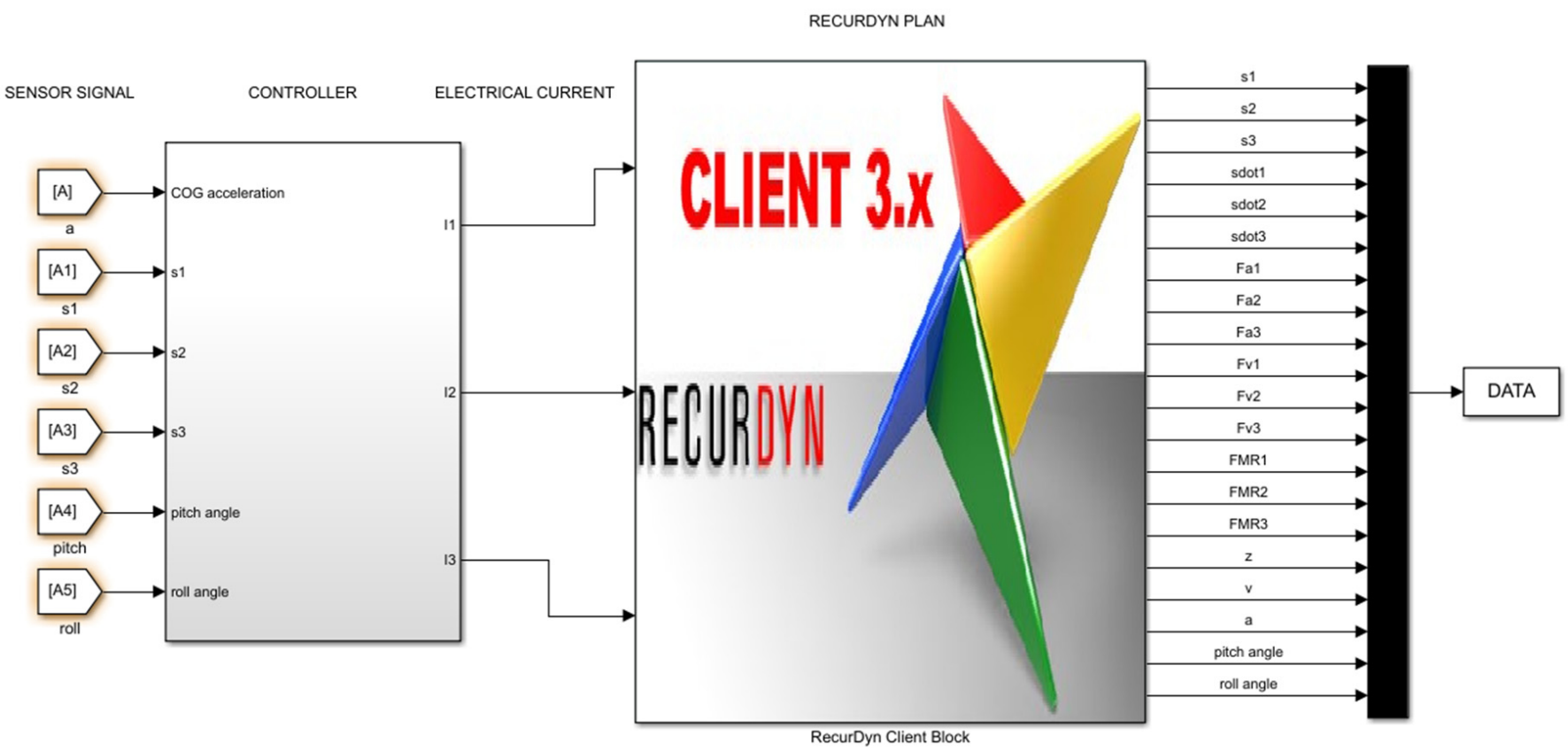

Figure 12. Co-simulation between MATLAB-RECURDYN.

Figure 13 shows the simulation setup in the case of non-zero pitch and roll angles: $\theta=7^{\circ}$ and $\Phi=7^{\circ}$, respectively. At the outset, as the right main landing gear makes contact with the ground, the left main landing gear and nose landing gear are still in the air. The initial velocity of the helicopter body is set to be equal to the designed sink speed of $2.54 \mathrm{~m} / \mathrm{s}$, following the standards outlined in FAA Part 27 [14]. Therefore, the speeds of the latter landing gears at the moment they touch the ground would be significantly larger than the designed sink speed, with a negative effect on damping the landing impact.

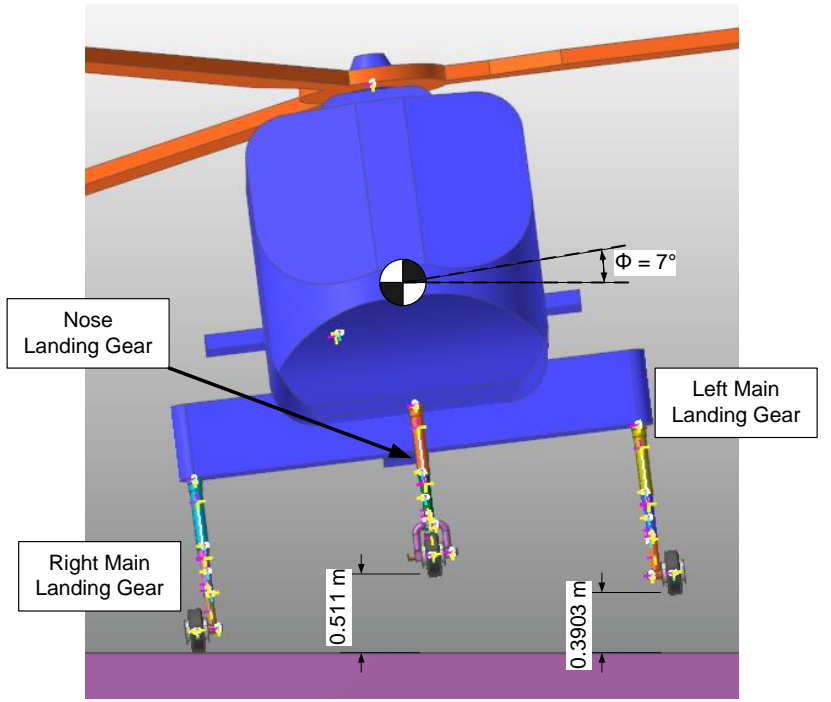

(a)

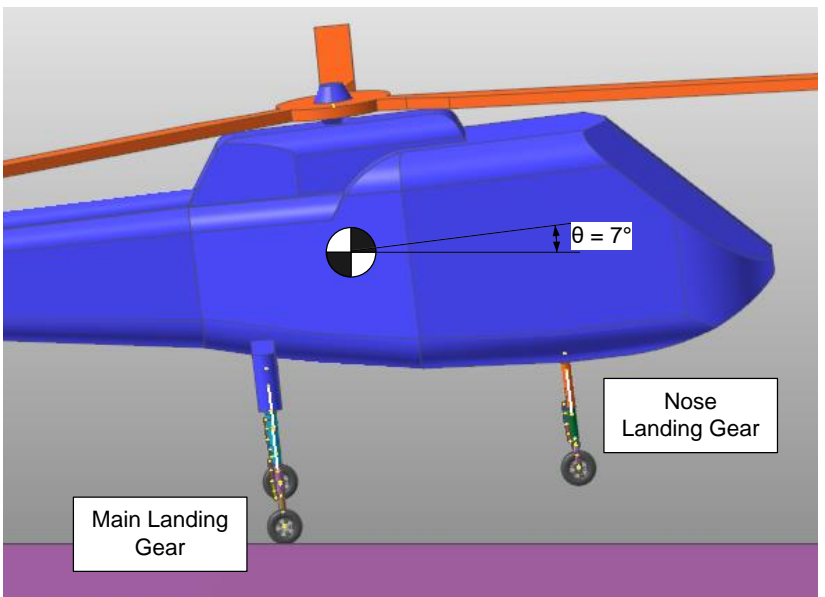

(b)

Figure 13. The simulation setup at $\theta=7^{\circ}$ and $\Phi=7^{\circ}$. (a) Front view; (b) Side view. 
Figure 14 shows the simulation results of the landing gears using different control methods in the case of $\theta=7^{\circ}$ and $\Phi=7^{\circ}$. In this landing case, the right main landing gear makes contact with the ground first, and then soon after it slips due to the dynamic asymmetry. During the slip, this landing gear releases energy. As the left main landing gear touches the ground, the slipping ends, and both of the main landing gears start to absorb energy. This makes the shapes of the load-stroke curves in Figure 14f,g more complex than the typical curves produced by single landing gear tests. Because the initial sink speed of the nose landing gear is much higher than it was designed for, this landing gear with the passive damper cannot absorb all of the potential and kinetic energy during touchdown. Hence, the nose landing gear rebounds, and thus its damping force nearly decreases to zero during the release phase of the damper, which can be verified in the efficiency curve in Figure 14h.

Both the traditional skyhook controller and the skyhook extended controller exhibited better performance than the passive damper in this off-normal landing attitude condition. All damping forces remained positive during the release phase, so there were no rebounds. In particular, the skyhook extended controller showed better performance than the passive damper and traditional skyhook controller. The damper using the proposed controller produced the smallest magnitude of peak values in displacement, velocity, and acceleration at the helicopter's center of gravity. This signifies that the proposed controller is able to mitigate more vibration for the simulated helicopter during touchdown, which may enhance pilot and crew comfort in adverse landing conditions.

Figure 15 compares the performance of the control methods in mitigating acceleration with the cost defined as in Equation (6) in differing initial pitch and roll angles. As can be seen, both skyhook controllers produced a significantly smaller cost than the passive damper. For the cases where $\Phi=0^{\circ}$ and $\theta<3^{\circ}$, the traditional skyhook controller showed almost the same performance as the skyhook extended controller due to close-to-symmetric landing attitudes. In other cases, the skyhook extended controller reduced the cost to a greater extent than the traditional skyhook. The biggest improvement of the proposed controller over the traditional skyhook was about $10 \%$ at $\theta=7^{\circ}$ and $\Phi=7^{\circ}$. Generally, the skyhook extended controller exhibited better performance in reducing acceleration than both the traditional skyhook controller and passive damper in all ranges of initial pitch and roll angles. 


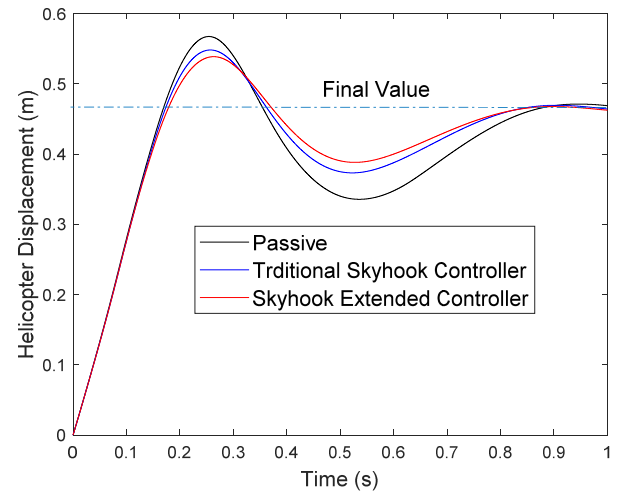

(a) COG displacement

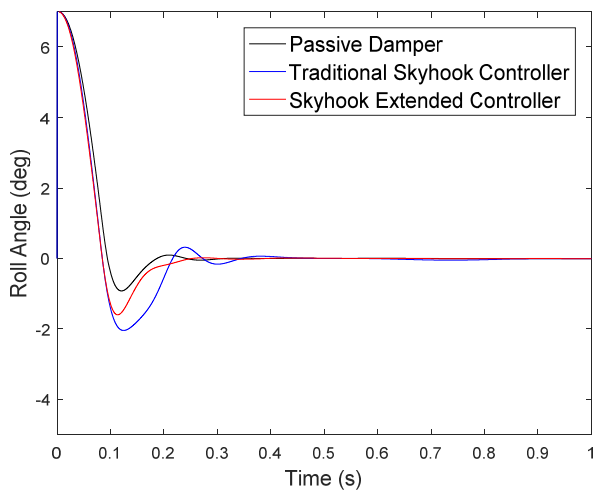

(c) Roll angle

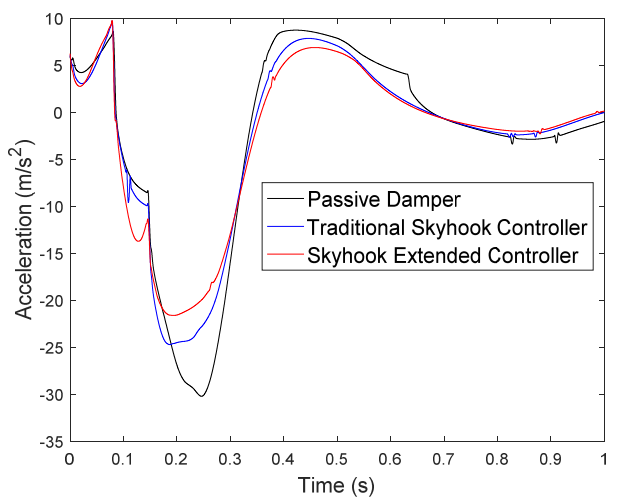

(e) COG acceleration

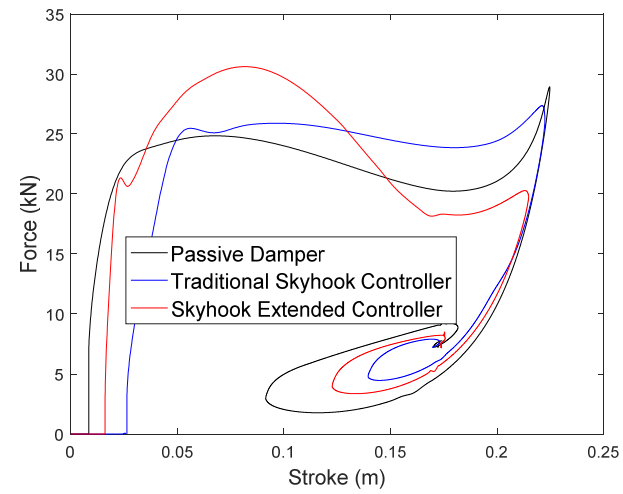

(g) Load-stroke curve of left main landing gear

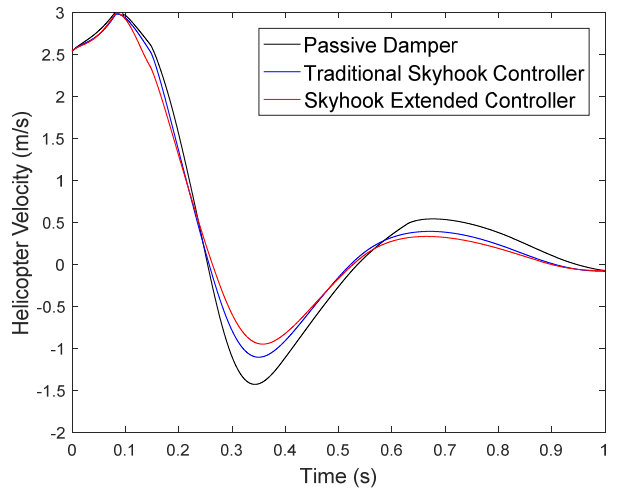

(b) COG velocity

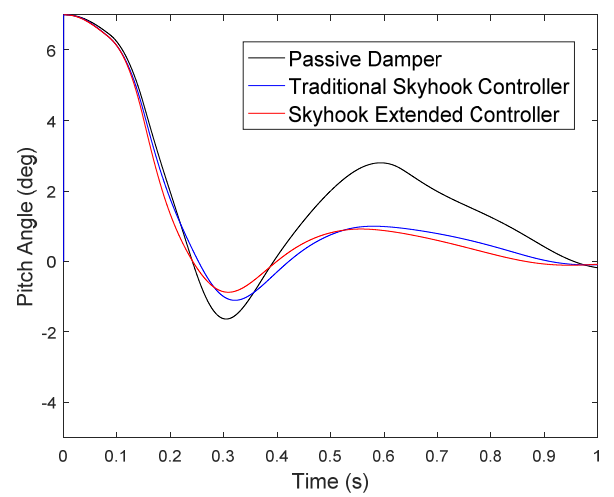

(d) Pitch angle

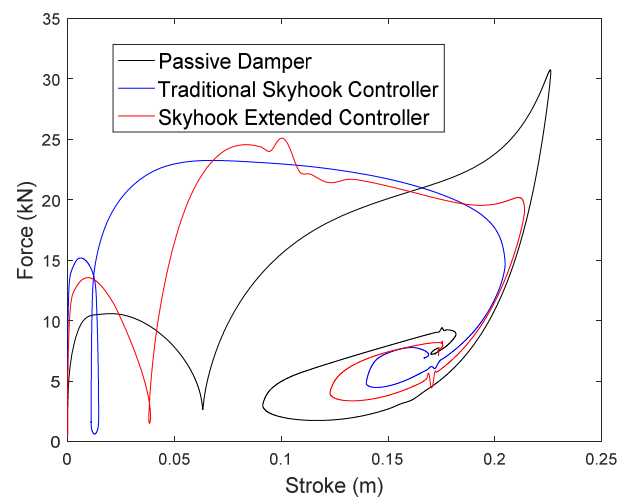

(f) Load-stroke curve of right main landing gear

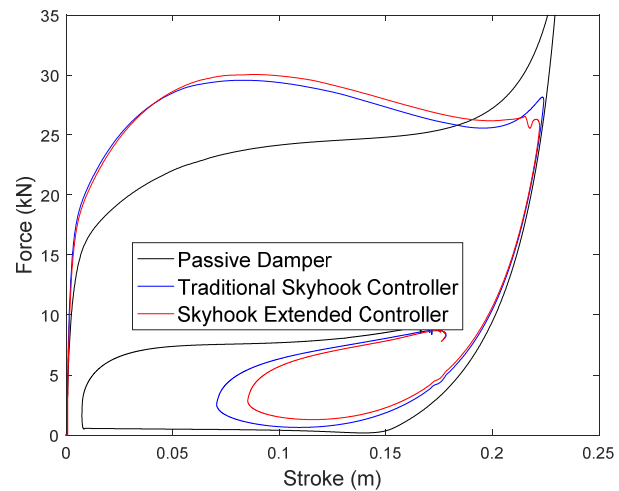

(h) Load-stroke curve of nose landing gear

Figure 14. Comparative simulation results of the passive damper, traditional skyhook controller, and skyhook extended controller at $\theta=7^{\circ}$ and $\Phi=7^{\circ}$. 


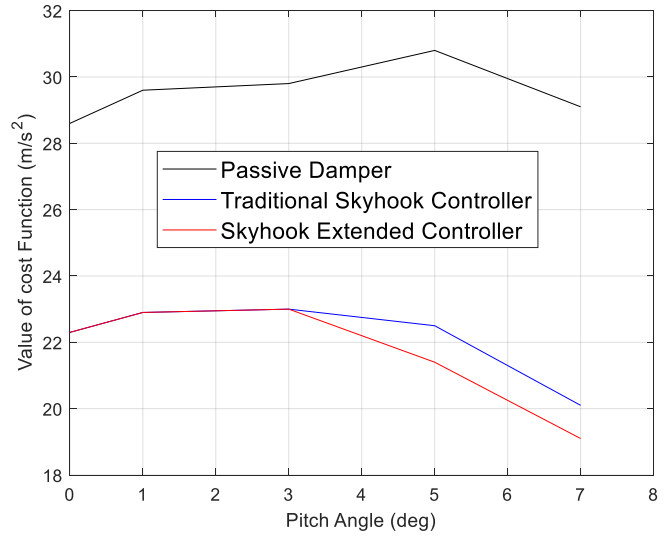

(a) $\Phi=0^{\circ}$

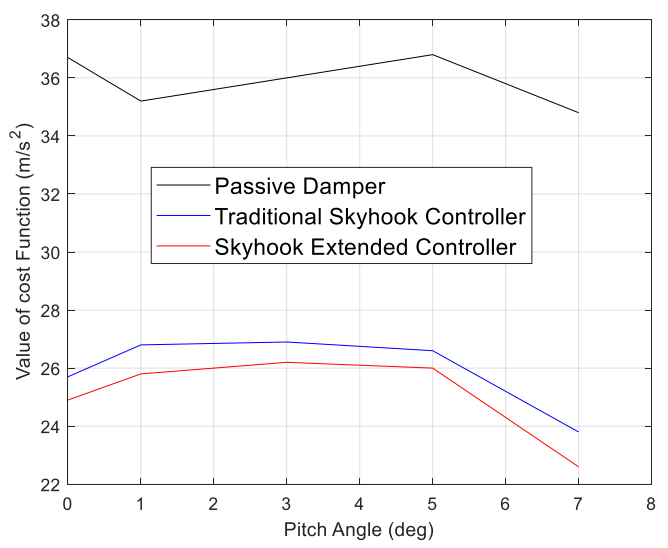

(c) $\Phi=3^{\circ}$

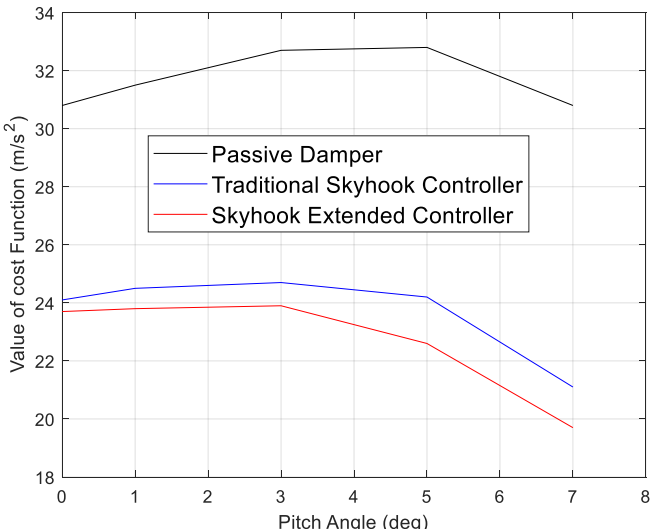

(b) $\Phi=1^{\circ}$

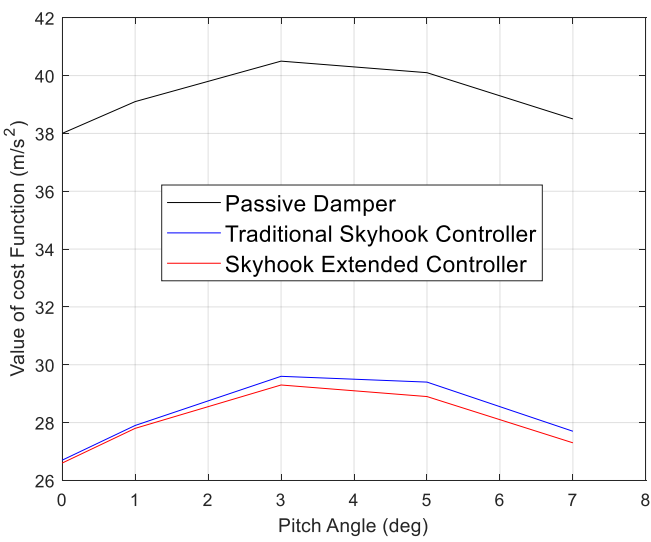

(d) $\Phi=5^{\circ}$

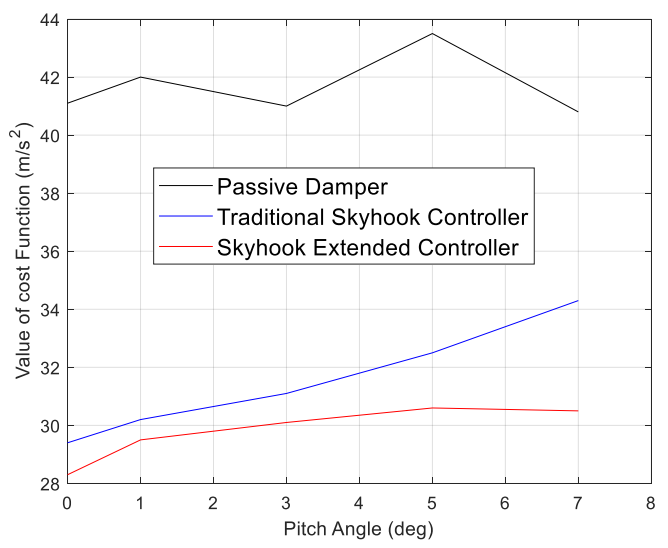

(e) $\Phi=7^{\circ}$

Figure 15. The value of cost function in differing pitch and roll angles.

\section{Conclusions}

This research adopted a new semi-active controller, called the skyhook extended controller, to reduce the center of gravity acceleration of a helicopter with three landing gears equipped with magnetorheological dampers in differing off-normal landing scenarios. In this research, the Nelder-Mead simplex method was used to find the optimal skyhook gains. Instead of time-consuming and costly experiments (e.g., flight/drop tests), numerical simulations were executed by using co-simulation with MATLAB and RECURDYN to demonstrate the effectiveness of the proposed controller with verified physics models. The proposed controller minimized the helicopter acceleration at the center of gravity to a greater extent than the passive damper and the traditional skyhook controller. In future 
studies, the controller will be extended not only to cover more adverse and challenging landing conditions such as landing on a ship or a slope, but also to improve the robustness in differing landing scenarios and uncertainties.

Author Contributions: Data curation, Q.V.L. and D.-S.J.; Formal analysis, Q.V.L. and D.-S.J.; Investigation, D.-S.J.; Methodology, D.-S.J. and J.-H.H.; Project administration, J.-H.H.; Software, Q.V.L.; Supervision, D.-S.J. and J.-H.H.; Writing—original draft, Q.V.L.; Writing-review and editing, D.-S.J. and J.-H.H. All authors have read and agreed to the published version of the manuscript.

Funding: This work was funded by the Ministry of Trade, Industry \& Energy (MOTIE, Korea), grant number 10073291.

Institutional Review Board Statement: Not applicable.

Informed Consent Statement: Not applicable.

Acknowledgments: This work was supported by the Technology Innovation Program (intelligent landing gear with variable damping force for 1500lb class) (10073291).

Conflicts of Interest: The authors declare no conflict of interest.

\section{References}

1. Rotaru, C.; Todorov, M. Helicopter Flight Physics. In Flight Physics-Models, Techniques and Technologies; Volkov, K., Ed.; IntechOpen: London, UK, 2018; ISBN 978-953-51-3807-5.

2. Wagtendonk, W.J. Principles of Helicopter Flight; Aviation Supplies and Academics, Inc.: Newcastle, WA, USA, 2015; ISBN 978-161954-299-0.

3. Cheng, M.; Chen, Z. Semi-Active Helicopter Ground Resonance Suppression Using Magnetorheological Technology. In Proceedings of the ASME 2017 Conference on Smart Materials, Adaptive Structures and Intelligent Systems, Snowbird, UT, USA, 18-20 September 2017; p. V002T03A015. [CrossRef]

4. Federal Aviation Administration (FAA). Helicopter Instructor's Handbook; U.S. Department of Transportation Federal Aviation Administration: Washington, DC, USA, 2012.

5. Hwang, J.-U.; Hwang, J.-H.; Bae, J.-S.; Hyun, Y.-O.; Lim, K.-H.; Kim, D.-M.; Kim, T.-W. Semi-Active Control of Helicopter Landing Gear Using Magneto-Rheological Damper. J. Korean Soc. Aeronaut. Space Sci. 2008, 36, 346-351. [CrossRef]

6. Saleh, M. Analysis, Design Optimization, and Semi-Active Control of Skid Landing Gear Featuring Bi-Fold Magnetorheological Dampers. Ph.D. Thesis, Concordia University, Montréal, QC, Canada, 2017.

7. Powell, L.A.; Hu, W.; Wereley, N.M. Magnetorheological Fluid Composites Synthesized for Helicopter Landing Gear Applications. J. Intell. Mater. Syst. Struct. 2013, 24, 1043-1048. [CrossRef]

8. Choi, Y.-T.; Robinson, R.; Hu, W.; Wereley, N.M.; Birchette, T.S.; Bolukbasi, A.O.; Woodhouse, J. Analysis and Control of a Magnetorheological Landing Gear System for a Helicopter. J. Am. Helicopter. Soc. 2016, 61, 1-8. [CrossRef]

9. Han, C.; Kim, B.-G.; Choi, S.-B. Design of a New Magnetorheological Damper Based on Passive Oleo-Pneumatic Landing Gear. J. Aircr. 2018, 55, 2510-2520. [CrossRef]

10. Guglielmino, E.; Sireteanu, T.; Stammers, C.W.; Ghita, G.; Giuclea, M. Semi-Active Suspension Control; Springer: London, UK, 2008; ISBN 978-1-84800-230-2.

11. Kashem, S.; Nagarajah, R.; Ektesabi, M. Vehicle Suspension Systems and Electromagnetic Dampers; Springer Tracts in Mechanical Engineering; Springer: Singapore, 2018; ISBN 978-981-10-5477-8.

12. Kiefer, J.; Ward, M.; Costello, M. Rotorcraft Hard Landing Mitigation Using Robotic Landing Gear. J. Dyn. Syst. Meas. Control 2016, 138, 031003. [CrossRef]

13. AS 550 Fennec. Available online: https://fas.org/man/dod-101/sys/ac/row / fennec.htm (accessed on 22 October 2020).

14. Federal Aviation Administration. Part 27-Airworthiness Standards: Normal Category Rotorcraft. Available online: https: / / www.law.cornell.edu/cfr/text/14/27.725\#: \{\}:text=\%C2\%A7\%2027.725\%20Limit\%20drop\%20test.\&text=(2)\%2 0Any\%20lesser\%20height\%2C,in\%20normal\%20power\%2Doff\%20landings (accessed on 10 February 2021).

15. Han, C.; Kang, B.-H.; Choi, S.-B.; Tak, J.M.; Hwang, J.-H. Control of Landing Efficiency of an Aircraft Landing Gear System with Magnetorheological Dampers. J. Aircr. 2019, 56, 1980-1986. [CrossRef]

16. Luong, Q.V.; Jang, D.-S.; Hwang, J.-H. Intelligent Control Based on a Neural Network for Aircraft Landing Gear with a Magnetorheological Damper in Different Landing Scenarios. Appl. Sci. 2020, 10, 5962. [CrossRef]

17. Luong, Q.V.; Jang, D.-S.; Hwang, J.-H. Robust Adaptive Control for an Aircraft Landing Gear Equipped with a Magnetorheological Damper. Appl. Sci. 2020, 10, 1459. [CrossRef]

18. Choi, S.-B.; Han, Y.-M. Magnetorheological Fluid Technology Applications in Vehicle Systems, 1st ed.; Taylor \& Francis Group: Abingdon-on-Thames, UK, 2012; ISBN 978-0-429-11055-9.

19. Currey, N.S. Aircraft Landing Gear Design: Principles and Practices; AIAA Education Series; AIAA: Reston, VA, USA, 1988; ISBN 0930403. 
20. Yazici, H.; Sever, M. Active Control of a Non-Linear Landing Gear System Having Oleo Pneumatic Shock Absorber Using Robust Linear Quadratic Regulator Approach. Proc. Inst. Mech. Eng. Part G J. Aerosp. Eng. 2018, 232, 2397-2411. [CrossRef]

21. Dong, X.M.; Xiong, G.W. Vibration Attenuation of Magnetorheological Landing Gear System with Human Simulated Intelligent Control. Math. Probl. Eng. 2013, 2013, 1-13. [CrossRef]

22. Karnopp, D.; Crosby, M.J.; Harwood, R.A. Vibration Control Using Semi-Active Force Generators. J. Eng. Ind. 1974, 96, 619-626. [CrossRef]

23. Lee, D.Y.; Nam, Y.J.; Yamane, R.; Park, M.K. Performance Evaluation on Vibration Control of MR Landing Gear. J. Phys. Conf. Ser. 2009, 149, 012068. [CrossRef]

24. Larson, J.; Menickelly, M.; Wild, S.M. Derivative-Free Optimization Methods. Acta Numer. 2019, 28, 287-404. [CrossRef]

25. Conn, A.R.; Vicente, L.N.; Scheinberg, K. Introduction to Derivative-Free Optimization; MPS-SIAM Series on Optimization; Society for Industrial and Applied Mathematics: Philadelphia, PA, USA; ISBN 978-0-89871-668-9.

26. Gao, F.; Han, L. Implementing the Nelder-Mead Simplex Algorithm with Adaptive Parameters. Comput. Optim. Appl. 2012, 51, 259-277. [CrossRef] 